\title{
EXETER
}

\section{A Cyclical Model of Exchange Rate Volatility}

\author{
Richard D. F. Harris ${ }^{\mathrm{a}}$, Evarist Stoja ${ }^{\mathrm{b}}$ and Fatih Yilmaz $^{\mathrm{c}}$ \\ Paper No 10/03 \\ April 2010
}

\begin{abstract}
In this paper, we investigate the long run dynamics of the intraday range of the GBP/USD, JPY/USD and CHF/USD exchange rates. We use a non-parametric filter to extract the low frequency component of the intraday range, and model the cyclical deviation of the range from the long run trend as a stationary autoregressive process. We find that the long run trend is time-varying but highly persistent, while the cyclical component is strongly mean reverting. This has important implications for modelling and forecasting volatility over both short and long horizons. As an illustration, we use the cyclical volatility model to generate out-of-sample forecasts of exchange rate volatility for horizons of up to one year under the assumption that the long run trend is fully persistent. As a benchmark, we compare the forecasts of the cyclical volatility model with those of the two-factor intraday range-based EGARCH model of Brandt and Jones (2006). Not only is the cyclical volatility model significantly easier to estimate than the EGARCH model, but it also offers a substantial improvement in out-of-sample forecast performance.
\end{abstract}

Keywords: Conditional volatility; Intraday range; Hodrick-Prescott filter.

${ }^{a}$ Xfi Centre for Finance and Investment, University of Exeter, Exeter, EX4 4PU, UK. Email: r.d.f.Harris@exeter.ac.uk (corresponding author).

${ }^{\mathbf{b}}$ School of Economics, Finance and Management, University of Bristol, 8 Woodland Road, Bristol, BS8 1TN, UK. Email: e.stoja@bristol.ac.uk.

${ }^{\mathbf{c}}$ BlueGold Capital Management LLP, $2^{\text {nd }}$ Floor, 4 Sloane Terrace, London SW1X 9DQ, UK. Email: fyilmaz@bluegoldcap.com. 


\section{Introduction}

There is now substantial evidence that financial market volatility is both time-varying and highly predictable (see, for example, Andersen et al., 2004). This has important implications for many applications in finance, including portfolio optimisation, risk measurement and option pricing, and has given rise to a large literature on volatility measurement and forecasting. As noted by Brandt and Jones (2006), the efficacy of a volatility model depends on a number of factors. The first is the adequacy of the proxy for unobserved volatility that is employed in the model. Traditional volatility proxies based on the squared demeaned return are unbiased estimators of the latent integrated variance because the integrated volatility is, by construction, the expectation of the squared demeaned return. However, measures based on the squared return are inefficient owing to the fact that they employ only a single measurement of the price each period and hence contain no information about the intra-period trajectory of the price. An improvement in efficiency can be obtained by using intraday data. Indeed, Andersen et al. (2004) show that under very general assumptions, the sum of squared intraday returns converges to the unobserved integrated volatility as the intraday interval goes to zero. However, the construction of realized volatility relies on high frequency data, which is not readily available for most assets over extended periods. Moreover, as the intraday frequency increases, market microstructure effects distort the measurement of returns, leading to an upward bias in realized volatility.

An alternative volatility proxy, and one that has experienced a significant renewed interest, is the intraday range, which is defined as the scaled difference between the intraday high and low prices. Building on the earlier results of Parkinson (1980), Garman and Klass (1980) and others, Alizadeh, Brandt and Diebold (2002) show that in addition to being significantly more efficient than the squared return, the intraday range is more robust than realized volatility to market microstructure noise. Moreover, a significant practical advantage of the intraday range is that in contrast with the high frequency data that are required for the construction of realized volatility, intraday high and low prices 
are readily available for almost all financial assets over extended periods of time. ${ }^{1}$ The intraday range has been employed in a number of conditional volatility models, including Chou (2005), who develops a conditional autoregressive range (CARR) estimator that is based on the conditional duration model of Engle and Russell (1998), and Brandt and Jones (2006), who extend the EGARCH model of Nelson (1991) using the intraday range in place of the absolute return. In both cases, the range-based GARCH estimators generate more accurate volatility forecasts than equivalent models based on squared returns.

The second factor that determines the efficacy of a volatility model is the specification of the process that governs volatility dynamics. Increasingly, evidence suggests that volatility is characterised by a multi-factor structure, with different dynamic processes governing the long run and short run dynamics of volatility. Engle and Lee (1999) introduce a component GARCH model, which decomposes volatility into a permanent long-run trend component and a transitory short-run component that is mean-reverting towards the long-run trend. ${ }^{2}$ Empirical evidence suggests that the two-factor GARCH model provides a better fit to the data than an equivalent one-factor model. Alizadeh et al. (2002) exploit the approximate log normality of volatility proxies based on the intraday range and estimate both one factor and two-factor range-based stochastic volatility models for the daily returns of a number of exchange rates using Gaussian maximum likelihood. They find that the evidence strongly supports a two-factor model with one highly persistent factor and one rapidly mean-reverting factor. Similarly, Brandt and Jones (2006) estimate one-factor and two-factor range-based EGARCH models for daily returns on the S\&P 500 index. They too show that volatility is well characterised by a two-factor model with one highly persistent factor and one strongly stationary factor. ${ }^{3}$

\footnotetext{
${ }^{1}$ For example, Datastream records the intraday range for most securities, including equities, currencies and commodities, going back to about 1985.

${ }^{2}$ See also Christoffersen et al (2008), who derive a two-component version of the GARCH model developed by Heston and Nandi (2000), which permits a closed-form solution for option valuation.

${ }^{3}$ See also Gallant, Hsu and Tauchen (1999), Chernov, Ghysels, Gallant and Tauchen (2003), Barndorff-Nielsen and Shephard (2001) and Bollerslev and Zhou (2002), Maheu (2005).
} 
The finding that volatility has both a highly persistent factor and a strongly stationary factor has important implications for modelling and forecasting volatility over both short and long horizons. In particular, using the range-based two-factor EGARCH model, Brandt and Jones (2006) show that there is substantial predictability in volatility at horizons of up to one year. This is in contrast with earlier studies, such as West and Cho (1996) and Christoffersen and Diebold (1999), both of which conclude that volatility predictability is essentially a short horizon phenomenon. It is clear that the success of two-factor models in forecasting volatility rests on their ability to correctly identify the current long run level of volatility, and to exploit the dynamics of the short run component to forecast reversion of volatility to the current trend. To the extent that the long run component is close to being non-stationary, its dynamics are only relevant, if at all, over much longer forecasting horizons.

Motivated by the above interpretation of two-factor volatility models, we explore an alternative, very simple approach to modelling and forecasting volatility over both short and long horizons. In particular, we estimate the long run trend in measured volatility using the non-parametric filter of Hodrick and Prescott (1997). We then model the dynamics of the short run component as a stationary autoregressive process around this long run trend. Our measure of volatility is based on the intraday range in order to exploit the efficiency improvements that it offers over the squared return. However, rather than apply the non-parametric filter directly to the intraday range, we separately extract the long run components of intraday high and low prices, and then use these to construct an estimate of the cyclical component of volatility. This is motivated by the fact that intraday high and low prices are more likely to satisfy the assumptions of the nonparametric filter and hence give reliable estimates of the underlying long run trend in volatility.

We use this approach to model the volatility dynamics of the GBP/USD, JPY/USD and CHF/USD daily exchange rates over the period 1 January 1987 to 28 April 2008. Consistent with the findings of Engle and Lee (1999), Alizadeh et al. (2002) and Brandt 
and Jones (2006), we show that the long run component is characterised by a timevarying but highly persistent trend, while the short run component is strongly meanreverting to this trend. We use the model to generate out-of-sample forecasts of exchange rate volatility. We assume that over the forecast horizon, the long run component of volatility follows a random walk and use the estimated parameters of the autoregressive

model to forecast the deviation of volatility from the long run component. As a benchmark, we compare the forecasts of our model with those of the two-factor rangebased EGARCH model of Brandt and Jones (2006), which explicitly models the long run component of volatility parametrically as an EGARCH process. Following the approach of Brandt and Jones (2006), we forecast volatility up to one year ahead, and use a rangebased volatility proxy to evaluate the forecasts from each model. In almost all cases, the cyclical volatility model provides a substantial improvement in forecast performance over the two-factor EGARCH model, in terms of both accuracy and informational content. The improvement in performance is particularly evident over shorter horizons where the random walk assumption for the long trend is most likely to be a good approximation. A significant practical advantage of the cyclical volatility model is the ease with which it can be estimated relative to other two-factor volatility models.

The outline of the remainder of this paper is as follows. In Section 2 we present the theoretical framework. Section 3 describes the data and evaluation criteria. Section 4 presents the empirical results. Section 5 concludes.

\section{Theoretical Background}

Suppose that the log price of an asset, $p(t)$, follows a continuous-time diffusion given by

$$
d p(t)=\sigma^{2}(t) d W(t)
$$


where $d W(t)$ is the increment of a Wiener process and $\sigma^{2}(t)$ is the instantaneous variance, which is strictly stationary and independent of $d W(t) .{ }^{4}$ Suppose that the price is recorded at daily intervals $t=1, \ldots, T$. Then conditional on the sample path of $\sigma^{2}(t)$, the daily logarithmic return, $r_{t}=p_{t}-p_{t-1}$, is normally distributed with integrated variance $\sigma_{t}^{2}=\int_{\mathrm{t}-1}^{t} \sigma^{2}(s) \mathrm{d} s$. The integrated variance, $\sigma_{t}^{2}$, is unobserved, but in principle can be estimated arbitrarily accurately using a measure of realized volatility based on intraday returns. In particular, Andersen et al. (2004) show that under very general conditions, the sum of squared intraday returns converges to the unobserved integrated volatility as the intraday interval goes to zero. However, the construction of realized volatility relies on high frequency intraday data, which are often not readily available over extended periods. Moreover, the accuracy of realized volatility as a proxy for integrated volatility is limited by the fact that as the intraday measurement frequency increases, market microstructure effects distort the measurement of returns, leading to an upward bias in estimated volatility (see, for example, Aït-Sahalia et al., 2005). An alternative approach is to construct an estimate of volatility based on the intraday range, given by

$$
\sigma_{R, t}^{2}=\frac{1}{4 \ln 2}\left(p_{t}^{H}-p_{t}^{L}\right)^{2}
$$

where $p_{t}^{H}=\max _{t-1<s<t} p(s)$ and $p_{t}^{L}=\min _{t-1<s<t} p(s)$. Parkinson (1980) shows that if $p(t)$ follows the diffusion process given by (1), the mean square error of the range-based estimator with respect to the true integrated variance is 5.2 times smaller than the mean square error of the squared daily return, and is hence equivalent to using realized variance based on intraday prices that are sampled every 4.6 hours. In practice, since prices are only observed at discrete intervals, the sample range under-estimates the true range of the continuous price. However, in liquid markets (such as for the major USD exchange rates used in this paper) this bias is likely to be negligible. A significant advantage of the

\footnotetext{
${ }^{4}$ For convenience, we assume that drift of the $\log$ price process is zero, which is a common assumption when dealing with short horizon returns. However, it is straightforward to relax this assumption.
} 
estimator given by (2) is that in contrast with high frequency data, intraday high and low prices are available on most assets over extended periods. Moreover, Alizadeh et al. (2002) show that the range-based estimator given by (2) is relatively robust to market microstructure noise.

In this paper, we employ the intraday range to investigate the short and long run dynamics of daily exchange rate volatility. In particular, we assume that the square root of the intraday range follows a two-factor process given by

$$
\sigma_{R, t}=q_{t}+\alpha\left(\sigma_{R, t-1}-q_{t-1}\right)+\varepsilon_{t}
$$

where $q_{t}$ is the long run trend component of the intraday range, $\sigma_{R, t}-q_{t}$ is the short run cyclical deviation of volatility from the long run trend and $\varepsilon_{t}$ is a random error term with zero mean and constant variance. The long run trend, $q_{t}$, is assumed to be a stationary but highly persistent process, but we leave its precise dynamics unspecified. The parameter $\alpha$ measures the speed of reversion of the cyclical component of volatility to the long run trend. This specification is motivated by the findings of a number of authors who show that volatility is characterised by a factor structure (see, for example, Engle and Lee, 1999; Alizadeh et al., 2002; Brandt and Jones, 2006).

We estimate the two-factor process given by (3) in two stages. First, we estimate the long-run component of volatility, $q_{t}$, non-parametrically using the filter of Hodrick and Prescott (1997), which extracts a low frequency non-linear trend from a time-series. Rather than apply the filter to the intraday range itself, we estimate the long run components of intraday high and low prices, $p_{t}^{H}$ and $p_{t}^{L}$ separately. This is motivated by the fact that intraday high and low prices are more likely to satisfy the assumptions of the non-parametric filter and hence give reliable estimates of the underlying long run trends in volatility. We set the smoothing parameter of the Hodrick Prescott filter to the commonly used value of 100 multiplied by the squared frequency of the data, which for daily data (assuming 240 trading days per year) is 5,760,000 (see, for example, Baxter and King, 1999). This implicitly assumes that volatility is linked to the business cycle. 
However, we also experimented with other values for the smoothing parameter and show that our results are robust across a large range of values. Defining the long run trend components of intraday high and low prices as $\tilde{p}_{t}^{H}$ and $\tilde{p}_{t}^{L}$, respectively, the long run trend of volatility is constructed as

$$
\tilde{q}_{t}=\left[\frac{1}{4 \ln 2}\left(\tilde{p}_{t}^{H}-\tilde{p}_{t}^{L}\right)^{2}\right]^{\frac{1}{2}}
$$

In the second step, we estimate an autoregressive model for the cyclical component:

$$
\sigma_{R, t}-\tilde{q}_{t}=a\left(\sigma_{R, t-1}-\tilde{q}_{t-1}\right)+v_{t}
$$

where $v_{t}$ is a zero mean random error. In order to forecast volatility using the cyclical volatility model, we assume that the long run trend follows a random walk over the

forecast horizon, so that $\hat{\tilde{q}}_{t+i}=\tilde{q}_{t}$ for all $i>0$, and use the estimated autoregressive parameter from (5) to forecast the cyclical component. The $n$-step ahead forecast of volatility in the cyclical volatility model is therefore given by

$$
\hat{\sigma}_{R, t+n}=\left(1-\hat{\alpha}^{n}\right) \tilde{q}_{t}+\hat{\alpha}^{n} \hat{\sigma}_{R, t}
$$

As $n \rightarrow \infty, \hat{\sigma}_{R, t+n}^{2} \rightarrow \tilde{q}_{t}$, with a speed that is determined by the estimated coefficient $\hat{\alpha}$.

The two-factor range-based EGARCH model

Brandt and Jones (2006) estimate one-factor and two-factor range-based EGARCH models for daily returns on the S\&P 500 index. They show that volatility is well characterised by a two-factor model with one highly persistent factor and one strongly stationary factor. As a benchmark against which to compare the cyclical volatility model, we estimate the two-factor range-based EGARCH model, given by 


$$
\begin{aligned}
& d_{t} \sim N\left(0.43+\ln \sigma_{t}, 0.29^{2}\right) \\
& \ln \sigma_{t}-\ln \sigma_{t-1}=\gamma_{1}\left(\ln q_{t-1}-\ln \sigma_{t-1}\right)+\phi_{1} x_{t-1}+\delta_{1} \frac{r_{t-1}}{\sigma_{t-1}} \\
& \ln q_{t}-\ln q_{t-1}=\gamma_{2}\left(\theta-\ln q_{t-1}\right)+\phi_{2} x_{t-1}+\delta_{2} \frac{r_{t-1}}{\sigma_{t-1}}
\end{aligned}
$$

where $\quad d_{t}=\ln \left(p_{t}^{H}-p_{t}^{L}\right), \quad r_{t}=p_{t}-p_{t-1}, \quad$ and $\quad x_{t}=\left(d_{t}-0.43-\ln \sigma_{t}\right) / 0.29 \quad$ is the standardised deviation of the log range from its expected value. We also estimate a one factor range-based EGARCH model derived by setting $\ln q_{t}=\theta$ so that the long run trend is constant. In order to forecast volatility using the EGARCH model, the shocks $x_{t+s}$ and $r_{t+s}$ are set to zero for all $s \geq 1$. The 1-step ahead forecast of volatility using the EGARCH model is therefore given by

$$
\ln \hat{\sigma}_{t+1}=\left(1-\hat{\gamma}_{1}\right) \ln \sigma_{t}+\hat{\gamma}_{1} \ln q_{t}+\hat{\phi}_{1} x_{t}+\hat{\delta}_{1} \frac{r_{t}}{\sigma_{t}}
$$

The 2-step ahead forecast is given by

$$
\begin{aligned}
& \ln \hat{\sigma}_{t+2}=\left(1-\hat{\gamma}_{1}\right) \ln \hat{\sigma}_{t+1}+\hat{\gamma}_{1} \ln \hat{q}_{t+1} \\
& \ln \hat{q}_{t+1}=\left(1-\hat{\gamma}_{2}\right) \ln q_{t}+\hat{\gamma}_{2} \hat{\theta}+\hat{\phi}_{2} x_{t}+\hat{\delta}_{2} \frac{r_{t}}{\sigma_{t}}
\end{aligned}
$$

The $n$-step ahead forecast for $n \geq 3$ is given by

$$
\begin{aligned}
& \ln \hat{\sigma}_{t+n}=\left(1-\hat{\gamma}_{1}\right) \ln \hat{\sigma}_{t+n-1}+\hat{\gamma}_{1} \ln \hat{q}_{t+n-1} \\
& \ln \hat{q}_{t+n}=\left(1-\hat{\gamma}_{2}\right) \ln \hat{q}_{t+n-1}+\hat{\gamma}_{2} \hat{\theta}
\end{aligned}
$$


As $n \rightarrow \infty, \hat{\sigma}_{t+n}^{2} \rightarrow \exp (\hat{\theta})$, with a speed that is determined by the estimated coefficients $\hat{\gamma}_{1}$ and $\hat{\gamma}_{2}$.

\section{Data and Forecast Evaluation}

Data

We use the cyclical volatility model to forecast volatility for the GBP/USD, JPY/USD and $\mathrm{CHF} / \mathrm{USD}$ exchange rates. Daily data were obtained for the three exchange rates from Reuters for the period 01 January 1987 to 28 April 2008 and used to construct daily $\log$ returns. The period 01 January 1987 to 05 December 1988 (500 observations) is reserved for initial estimation of the volatility models, while the period 06 December 1988 to 28 April 2008 (5047 observations) is used for out-of-sample evaluation in which the estimation window of 500 observations is rolled forward daily. Table 1 reports summary statistics for the three log return series for the full sample of 5547 observations. Panel A reports the mean, standard deviation, skewness and excess kurtosis coefficients and the Bera-Jarque statistic, while Panel B reports the first six autocorrelation coefficients and the Ljung-Box Q statistic for autocorrelation up to six lags for both returns and squared returns. P-values are reported in parentheses. All three series are highly non-normal with positive excess kurtosis and negative skewness. The return series are serially uncorrelated, but squared returns are highly autocorrelated, indicative of volatility clustering.

\section{[Table 1]}

Panel A of Figure 1 plots the intraday range measure of standard deviation over the whole sample of 5547 observations together with the long run trend estimated using the Hodrick-Prescott filter. Panel B of Figure 1 plots the resulting cyclical component of the standard deviation. It is clear that the long run trend in volatility is time-varying and highly persistent, while the cyclical component is strongly mean-reverting, lending support to the two-component representation of volatility. Panel $\mathrm{C}$ of Figure 1 plots the 
recursively estimated endpoint of the trend, which is used for forecasting volatility outof-sample, together with the trend estimated using the full sample. The recursively estimated trend is more volatile than the full-sample trend owing to the fact that at the end point of each rolling sample, the Hodrick-Prescott filter is implemented as a onesided filter, while for the corresponding observation within the full sample, it is a implemented as a two-sided filter which exploits information contained in subsequent observations to identify the trend ex post.

[Figure 1]

\section{Forecast evaluation}

Each of the two models is used to generate out-of-sample forecasts of the standard deviation of returns for horizons of up to 240 days over the evaluation period. The models are initially estimated using the first five hundred observations, and then the estimation period is rolled forward daily until the end of the sample is reached. Following Brandt and Jones (2006), from the point forecasts made at date $t$, we construct average forecasts of the standard deviation between $t+\tau_{1}$ and $t+\tau_{2}$ :

$$
\hat{\sigma}_{t}\left(\tau_{1}, \tau_{2}\right)=\frac{1}{\tau_{2}-\tau_{1}+1} \sum_{\tau=\tau_{1}}^{\tau_{2}} \hat{\sigma}_{t+\tau}
$$

We consider forecast horizons of 1, 5, 20, 60, 120 and 240 days. For the three shorter horizons, we take the average over the forecast horizon, i.e. $\left(\tau_{1}, \tau_{2}\right)=(1,1),(1,5)$ and $(1$, $20)$. For the three longer horizons, we use monthly averages, i.e. $\left(\tau_{1}, \tau_{2}\right)=(41,60),(101$, $120)$ and $(221,240)$. As a proxy for true volatility, we use the square root of the rangebased estimator of the variance given by (2). This is used to construct the average volatility over the each of the six forecast intervals:

$$
\sigma_{t}\left(\tau_{1}, \tau_{2}\right)=\frac{1}{\tau_{2}-\tau_{1}+1} \sum_{\tau=\tau_{1}}^{\tau_{2}} \sigma_{R, t+\tau}
$$


We evaluate the forecasting performance of the non-overlapping conditional variance forecasts $\hat{\sigma}_{i, t}\left(\tau_{1}, \tau_{2}\right)$ generated by model $i$ using two measures. The first is the root mean square error (RMSE) with respect to the true average volatility:

$$
R M S E=\left[\frac{1}{T} \sum_{t=1}^{T}\left(\sigma_{t}\left(\tau_{1}, \tau_{2}\right)-\hat{\sigma}_{i, t}\left(\tau_{1}, \tau_{2}\right)\right)^{2}\right]^{1 / 2}
$$

The second criterion is the Mincer and Zarnowitz (1969) regression for each model given by:

$$
\sigma_{t}\left(\tau_{1}, \tau_{2}\right)=\alpha_{i}+\beta_{i} \hat{\sigma}_{i, t}\left(\tau_{1}, \tau_{2}\right)+\varepsilon_{i, t}\left(\tau_{1}, \tau_{2}\right)
$$

The Mincer-Zarnowitz regression measures the efficiency of the forecasts from each model. In particular, if the model is weakly efficient, $\alpha_{i}=0$ and $\beta_{i}=1$. We test the null hypothesis of weak efficiency for each model $i$ and for each forecast interval, $\left(\tau_{1}, \tau_{2}\right)$. The R-squared coefficient from the Mincer-Zarnowitz regression reveals the explanatory power of the model, irrespective of its efficiency, and is thus a useful measure of the information content of a model's forecasts.

\section{Results}

Table 2 reports the RMSE given by (17) for the three conditional volatility models over the different forecasting intervals for the three currencies. Across all three models, the RMSE at first falls with the forecast horizon and then rises. This is explained by the fact that initially, the forecast interval increases from 1 day to 5 days and then to 20 days. By averaging forecasts over increasingly long intervals, the noise in the forecasts is reduced, and this tends to outweigh any reduction in accuracy arising from an increase in the forecast horizon. After the 20-day horizon, the forecast interval is fixed at 20 days, and so forecast accuracy reduces as the horizon increases. For the 2-factor EGARCH model, the deterioration in forecast accuracy is very pronounced at the 240-day horizon. Overall, the 
cyclical model offers the highest forecast accuracy in 12 of the 18 cases, followed by the 2 -factor EGARCH model in five of the 18 cases. In only one case does the 1-factor EGARCH offer the lowest RMSE, which is consistent with the component representation of volatility.

[Table 2]

Tables 3 to 8 report the estimation results of the Mincer-Zarnowitz regression given by (18). The tables report the estimated regression parameters, the standard errors of these estimates, the regression R-squared statistic and the F-statistic to test the null hypothesis of conditional unbiasedness. In line with the results for the RMSE reported in Table 2, the R-squared generally increases for horizons up to 20 days, and then falls, reflecting initially the reduction in noise from extending the interval over which the forecasts are averaged, and then a reduction in performance from extending the forecasting horizon. For the short horizon forecasts (Tables 3 to 5), the cyclical volatility model has substantial explanatory power. Across all three currencies, the average value of the Rsquared statistic is $15.4 \%$ for the one-day forecasts, $30.5 \%$ for the five-day forecasts and $38.3 \%$ for the 20-day forecasts. The explanatory power for the two-factor EGARCH model is generally considerably lower $(10.7 \%, 22.7 \%$ and $31.8 \%$, respectively), and for the one-factor EGARCH model, lower still $(8.4 \%, 15.1 \%$ and $18.9 \%$, respectively). Of the nine short horizon forecasts, the highest explanatory power is offered by the cyclical volatility model in seven cases, and by the two-factor EGARCH model in two cases. However, where the explanatory power of the two-factor EGARCH model is higher than that of the cyclical volatility model, the differences are relatively small. The highest explanatory power for short horizon forecasts of any of the three models is $43.5 \%$ for the 20-day forecasts of the cyclical volatility model for the GBP. In all cases, the estimated slope coefficient is lower than unity and declines monotonically with the forecast horizon. The null hypothesis of conditional unbiasedness is rejected in all cases at the five percent significance level, but the rejection is notably stronger for the one-factor EGARCH model than for either of the two-factor models. 
[Tables 3 to 5]

For the long horizon forecasts (Tables 6 to 8), the explanatory power of the three models declines relative to the 20-day forecasts as the forecast horizon increases. For the cyclical model, the average R-squared statistic across the three currencies is $22.2 \%$ for 60 -day forecasts, $10.1 \%$ for 120 -day forecasts and $4.8 \%$ for 240 -day forecasts. Again, this is higher than either of the two EGARCH models. In many cases, the two-factor EGARCH model has higher explanatory power than the one-factor EGARCH model, although the differences are generally small. At the 240-day horizon, the explanatory power of the two-factor EGARCH model falls to zero for all three currencies. In contrast, the cyclical volatility model is able to explain $11.5 \%$ of the variation in volatility for the CHF at the 240-day horizon. Note, however, that the estimated slope coefficients fall significantly over longer forecast horizons, and indeed for the CHF at the 240-day horizon, the estimated slope coefficient is significantly negative for the cyclical volatility model.

[Tables 6 to 8 ]

We now explore the sensitivity of the cyclical model's performance to the choice of smoothing parameter in the Hodrick-Prescott filter. In particular, Figure 2 reports the Rsquared coefficient from the Mincer-Zarnowitz regression for values of the smoothing parameter from zero to $10^{13}$. Results are reported for each currency and for each of the six different forecast intervals. A smoothing parameter of zero corresponds to no trend. In this case, the forecast of the next period's volatility is simply equal to the current period's volatility. As the smoothing parameter increases, the estimated trend becomes more linear. With a smoothing parameter of $10^{13}$ - the highest value that we consider - the trend estimated over the full sample is visually indistinguishable from a linear trend. Figure 2 reveals that forecast performance at first increases with the value of the smoothing parameter and then decreases, and that this is true for all six forecast horizons and for all three currencies. In almost all cases, the optimal smoothing parameter is between $10^{4}$ and $10^{6}$. This is reasonably close to the smoothing parameter used in the results reported above $\left(0.576 \times 10^{7}\right)$ and for the GBP and JPY, the reduction in 
performance from using the higher value is relatively small. For the $\mathrm{CHF}$, the difference is more pronounced. Although not reported, a similar pattern emerges for the RMSE of the model's forecasts, with the most accurate forecasts generated by intermediate value of the smoothing parameter. Indeed, the optimal value of the smoothing parameter in terms of RMSE appears to be even closer to the 'default' value that we have used.

[Figure 2]

\section{Conclusion}

The finding that volatility has both a highly persistent component and a strongly stationary component has important implications for modelling and forecasting volatility over both short and long horizons. In this paper, we develop a simple yet effective model for forecasting volatility that is based on a decomposition of the intraday range measure of volatility into its trend and cycle components. Using a non-parametric filter, we are able to estimate the long run trend in volatility without having to specify its dynamics. Modelling the cyclical deviation of volatility from the long run trend as a simple autoregressive process then allows us to forecast volatility under the assumption that the trend component follows a random walk over the forecast horizon. We show that out-ofsample forecasts generated by the cyclical volatility model are able to explain a substantial fraction of the variation in actual volatility at horizons of up to one year. The model generally outperforms the two-factor range-based EGARCH model of Brandt and Jones (2006), in terms of both forecast accuracy and informational content. Owing to its simplicity, the cyclical volatility model also offers a substantial computational advantage over the two-factor EGARCH model. Indeed, the estimation time for the cyclical volatility model was many orders of magnitude lower than for the EGARCH model.

The results reported in this paper, as encouraging as they are, are based on the simplest possible specification both for the long run trend component (which we leave unspecified but assume to follow a random walk over the forecast horizon) and the cyclical component (which we assume to follow a first order autoregressive process). A natural 
line of further investigation would be alternative specifications for these two components. Almost certainly, a higher order ARMA process would provide a better fit for the cyclical component in-sample, and consequently it would be interesting to establish whether this translates into an improvement in out-of-sample forecast performance. Similarly, in order to estimate the long run trend, we have employed the 'default' value of the smoothing parameter in the Hodrick-Prescott filter, thus linking the trend in volatility to the trend in the business cycle. While this is perhaps a reasonable assumption, it is clear from the results reported above that this is not the optimal value, and so it would be interesting to estimate this parameter from the data. Moreover, while the random walk assumption for the long run trend provides a good approximation for short horizon forecasts, it becomes increasingly unrealistic as the forecast horizon increases since the long run trend, while highly persistent is nevertheless stationary and hence mean-reverting. It would be straightforward to adapt the specification of the cyclical model to incorporate these dynamics. A further avenue for future research would be to extend the cyclical volatility model to the multivariate setting. 


\section{References}

Aït-Sahalia, Y., P. Mykland, and L. Zhang, 2005, "How Often to Sample a ContinuousTime Process in the Presence of Market Microstructure Noise", Review of Financial Studies 18, 351-416.

Alizadeh, S., M. Brandt and F. Diebold, 2002, "Range-Based Estimation of Stochastic Volatility Models", Journal of Finance 57, 1047-92.

Andersen, T., T. Bollerslev and F. Diebold, 2004, "Parametric and Nonparametric Measurements of Volatility", In: Aït-Sahalia, Y., Hansen, L.P. (Eds.), Handbook of Financial Econometrics, North-Holland, Amsterdam.

Baxter, M., and R. King, 1999, "Measuring Business Cycles: Approximate Band-Pass Filters for Economic Time Series”, Review of Economics and Statistics 81, 575-593.

Barndorff-Nielsen, O., and N. Shephard, 2001, "Non-Gaussian Ornstein-UhlenbeckBased Models and Some of Their Uses in Financial Economics", Journal of the Royal Statistical Society Series B 63, 167-241.

Bollerslev, T., and H. Zhou, 2002, "Estimating Stochastic Volatility Diffusions Using Conditional Moments of Integrated Volatility", Journal of Econometrics 109, 33-65.

Brandt, M., and F. Diebold, 2006, "A No-Arbitrage Approach to Range-Based Estimation of Return Covariances and Correlations", Journal of Business 79, 61-74.

Chernov, M., E. Ghysels, A. Gallant, and G. Tauchen, 2003, "Alternative Models for Stock Price Dynamics”, Journal of Econometrics 106, 225-257.

Chou, R., 2005, "Forecasting Financial Volatilities with Extreme Values: The Conditional Autoregressive Range (CARR) Model”, Journal of Money, Credit and Banking 37, 561-582.

Christoffersen, P., and F. Diebold, 2000, "How Relevant Is Volatility Forecasting for Financial Risk Management?” Review of Economics and Statistics 82, 1-11.

Christoffersen, P., K. Jacobs, C. Ornthanalai and Y. Wang, 2008, "Option Valuation with Long-run and Short-run Volatility Components", Journal of Financial Economics 90, 272-297.

Engle, R., and G. Lee, 1999, "A Permanent and Transitory Model of Stock Return Volatility", in Cointegration, Causality, and Forecasting: A Festschrift in Honor of Clive W. J. Granger, eds. R. F. Engle and H. White, New York: Oxford University Press, pp. 475-497. 
Engle, R., and J. Russell, 1998, "Autoregressive Conditional Duration: A New Model for Irregular Spaced Transaction Data", Econometrica 66, 1127-1162.

Gallant, A, C. Hsu, and G. Tauchen, 1999, "Using Daily Range Data to Calibrate Volatility Diffusions and Extract the Forward Integrated Variance", Review of Economics and Statistics 81, 617-631.

Garman, M., and M. Klass, 1980, "On the Estimation of Price Volatility from Historical Data”, Journal of Business 53, 67-78.

Heston, S., and S. Nandi, 2000, "A Closed-Form GARCH Option Pricing Model", Review of Financial Studies 13, 585-626.

Hodrick, R., and E. Prescott, 1997, Post-War US Business Cycles: An Empirical Investigation", Journal of Money, Credit and Banking 29, 1-16.

Maheu, J., 2005, “Can GARCH Models Capture Long-Range Dependence?” Studies in Nonlinear Dynamics and Econometrics 9, Article 1.

Nelson, D., 1991, "Conditional Heteroskedasticity in Asset Returns: A New Approach", Econometrica 59, 347-370.

Parkinson, M., 1980, "The Extreme Value Method for Estimating the Variance of the Rate of Return", Journal of Business 53, 61-65.

West, K., and D. Cho, 1995, "The Predictive Ability of Several Models of Exchange Rate Volatility", Journal of Econometrics 69, 367-391. 


\section{Panel A: Volatility and Long Run Trend}

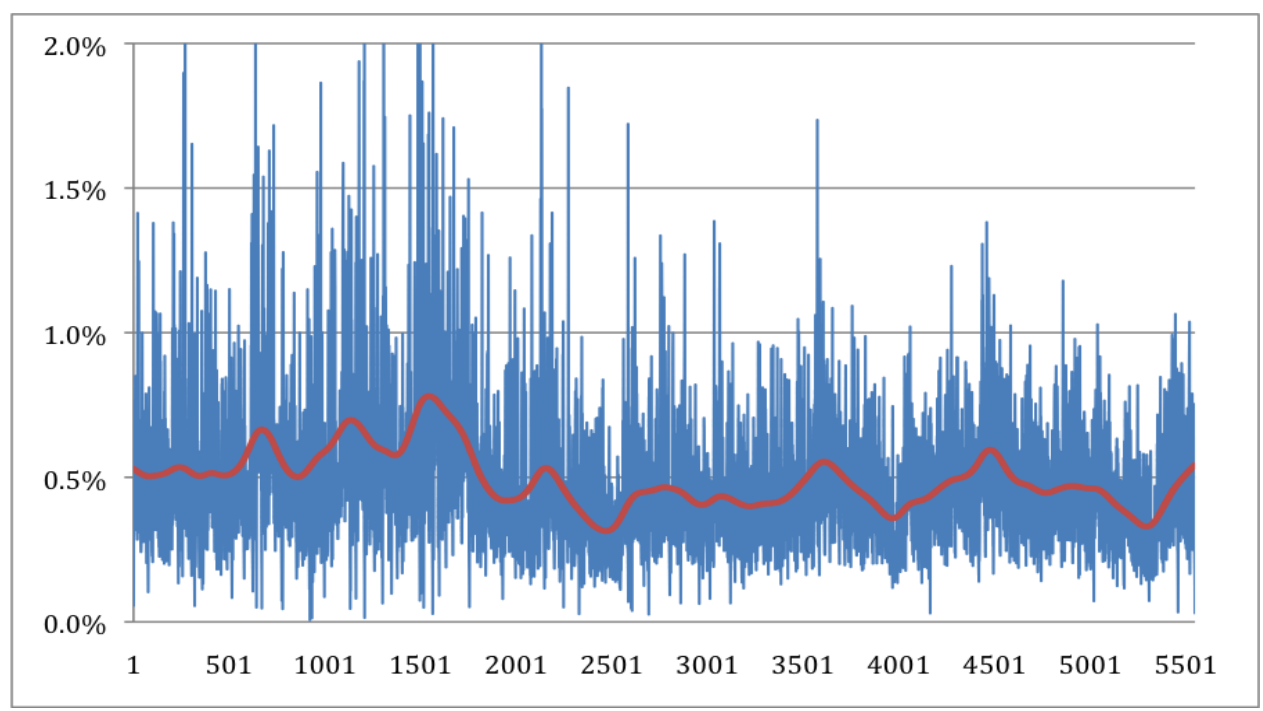

Panel B: Cyclical Component of Volatility

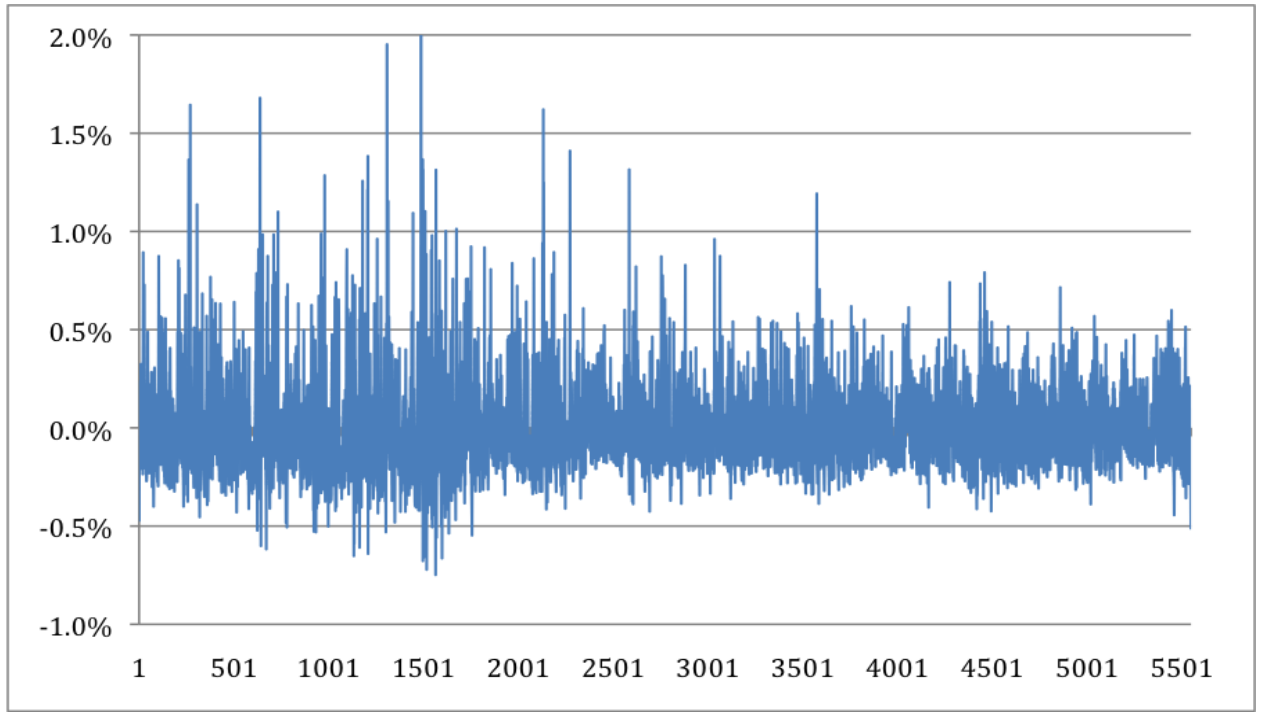

Notes: Panel A shows the range-based estimator of the standard deviation of log returns for the GBP estimated using equation (2) and the long run trend estimated using the Hodrick-Prescott filter with a smoothing parameter of 5,760,000. The sample period is $01 / 01 / 87$ to $28 / 04 / 08$. Panel $\mathrm{B}$ shows the cyclical component of volatility defined as the difference between the original series and the trend. Panel $\mathrm{C}$ shows the trend estimated using the whole sample and the end points of the trend estimated using a rolling window of 500 observations. 
Figure 1 (Continued) Decomposition of GBP Volatility into Trend and Cycle Components

Panel C: Full-Sample Trend and Recursively Estimated Trend

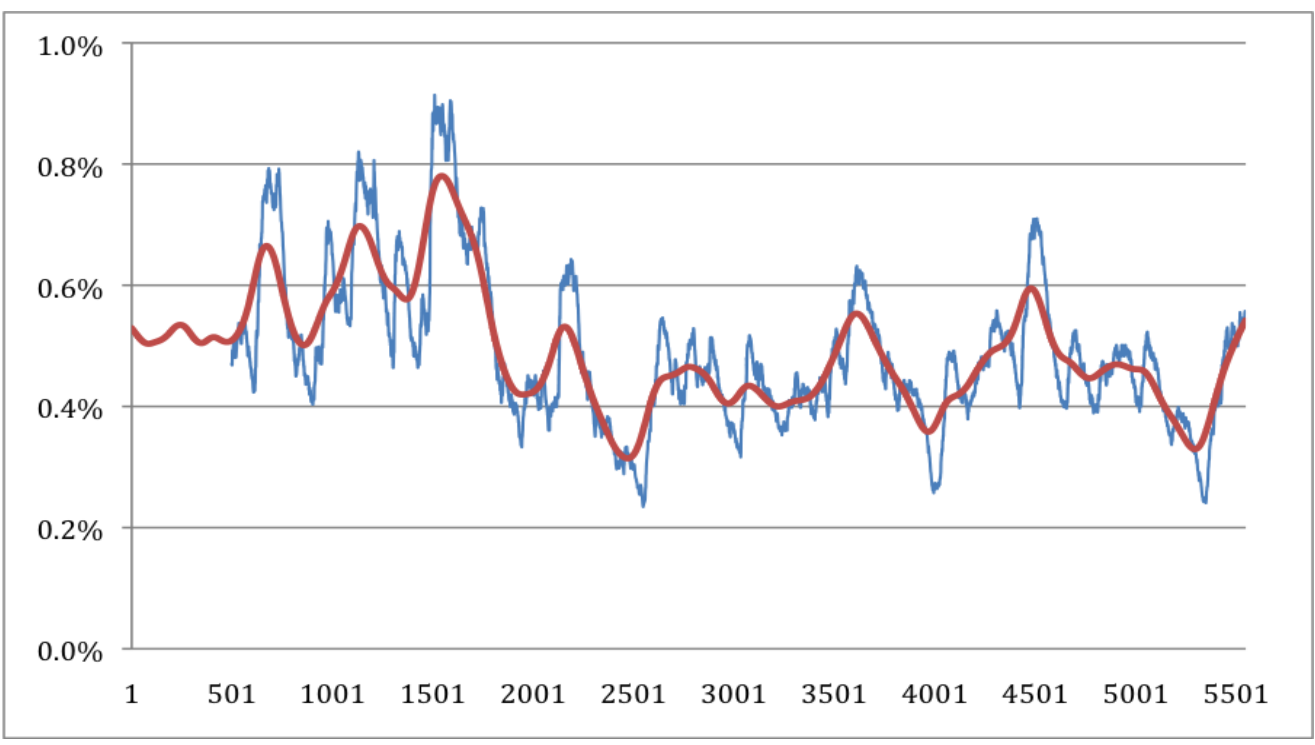

Notes: Panel A shows the range-based estimator of the standard deviation of log returns for the GBP estimated using equation (2) and the long run trend estimated using the Hodrick-Prescott filter with a smoothing parameter of 5,760,000. The sample period is $01 / 01 / 87$ to $28 / 04 / 08$. Panel B shows the cyclical component of volatility defined as the difference between the original series and the trend. Panel $\mathrm{C}$ shows the trend estimated using the whole sample and the end points of the trend estimated using a rolling window of 500 observations. 
Panel A: GBP

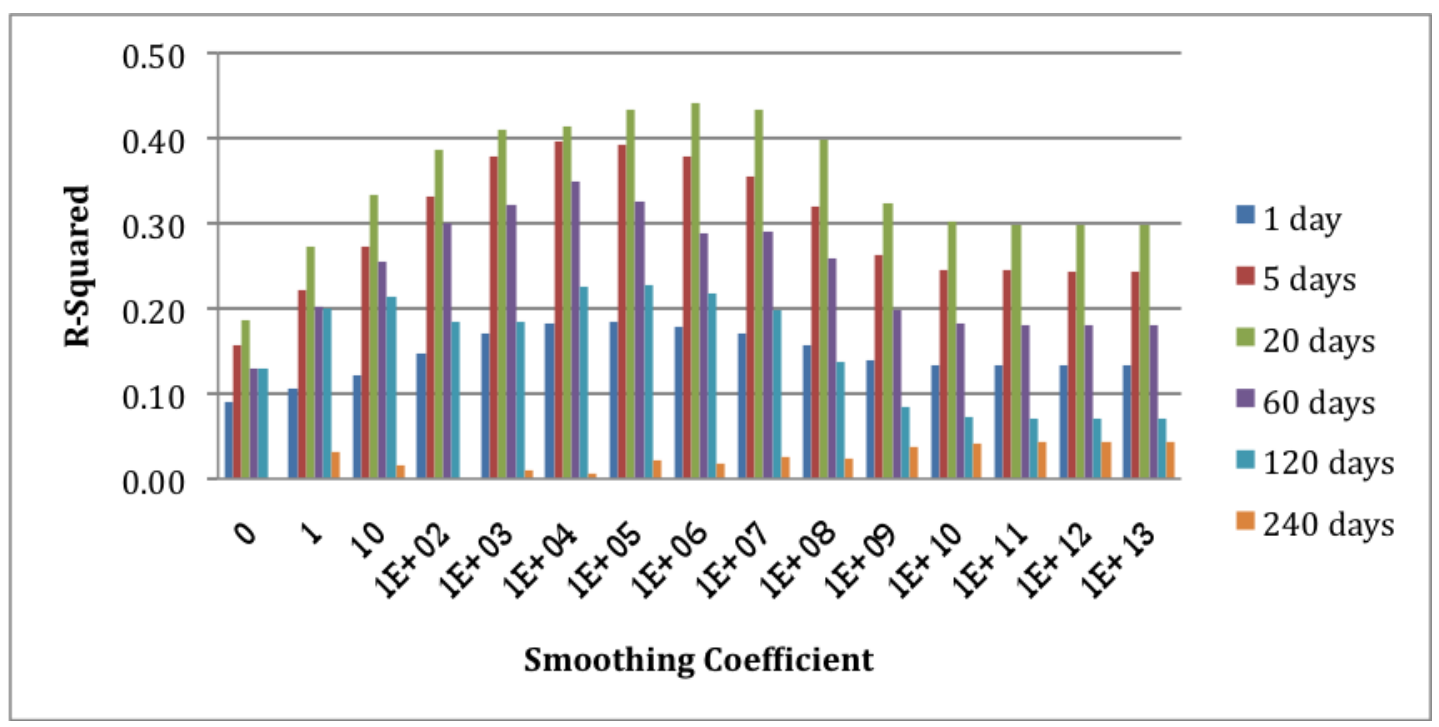

Panel B: CHF

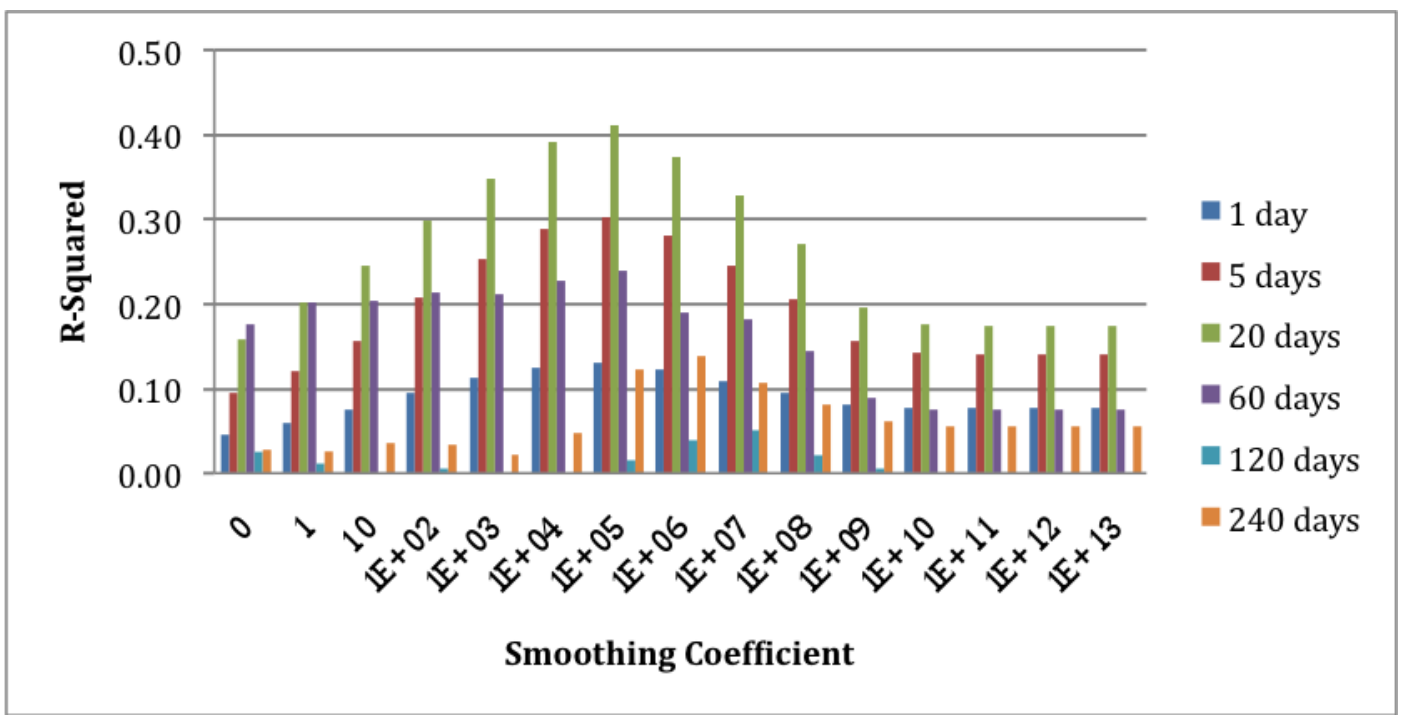

Notes: The Figure shows the value of the R-squared coefficient in the Mincer-Zarnowitz regression for different values of the smoothing parameter in the Hodrick-Prescott filter, for different forecast horizons and different currencies. The evaluation sample is 06 December 1988 to 28 April 2008 (5047 observations). 
Figure 2 (Continued) Sensitivity to Smoothing Coefficient

Panel C: JPY

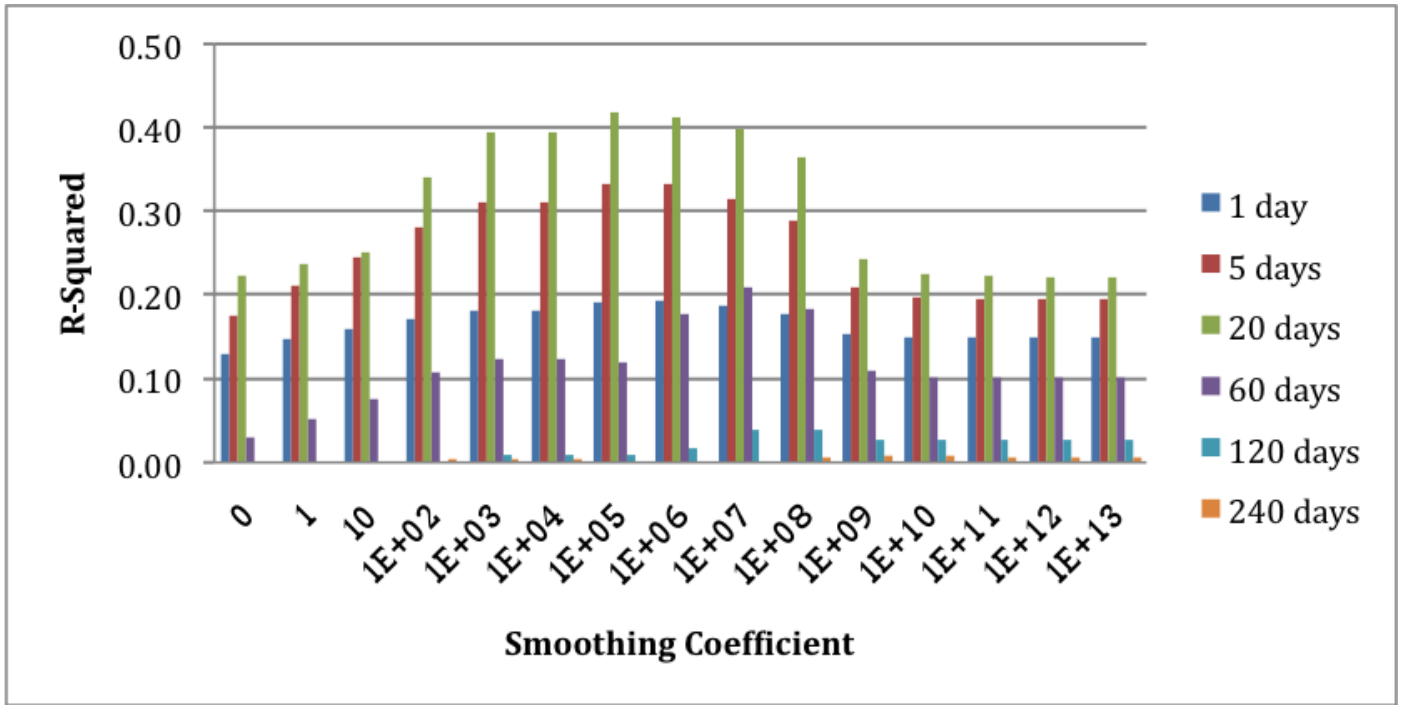

Notes: The Figure shows the value of the R-squared coefficient in the Mincer-Zarnowitz regression for different values of the smoothing parameter in the Hodrick-Prescott filter, and for different forecast horizons. The evaluation sample is 06 December 1988 to 28 April 2008 (5047 observations). 


\section{Panel A: Summary Statistics}

$\begin{array}{cccccc} & \text { Mean } & \begin{array}{c}\text { Standard } \\ \text { Deviation }\end{array} & \text { Skewness } & \begin{array}{c}\text { Excess } \\ \text { Kurtosis }\end{array} & \text { Bera-Jarque } \\ \text { GBP } & 0.005 \% & 0.589 \% & -0.207 & 3.050 & 662.268 \\ \text { CHF } & -0.008 \% & 0.715 \% & -0.112 & 1.701 & 763.295 \\ \text { JPY } & -0.007 \% & 0.689 \% & -0.494 & 5.213 & 839.624\end{array}$

\section{Panel B: Autocorrelations}

\section{Returns}

$\begin{array}{cccccccc} & 1 & 2 & 3 & 4 & 5 & 6 & \mathrm{Q} \\ \text { GBP } & -0.010 & 0.031 & -0.014 & -0.039 & 0.065 & 0.024 & 0.694(0.994) \\ \text { CHF } & -0.001 & -0.128 & 0.043 & -0.042 & 0.003 & -0.000 & 1.745(0.941) \\ \text { JPY } & 0.059 & -0.095 & -0.074 & -0.072 & 0.032 & 0.007 & 2.122(0.908)\end{array}$

\section{Squared Returns}

$\begin{array}{cccccccc} & 1 & 2 & 3 & 4 & 5 & 6 & \mathrm{Q} \\ \text { GBP } & 0.094 & 0.131 & 0.093 & 0.092 & 0.097 & 0.108 & 354.792(0.000) \\ \text { CHF } & 0.086 & 0.028 & 0.042 & 0.054 & 0.052 & 0.097 & 136.496(0.000) \\ \text { JPY } & 0.142 & 0.078 & 0.043 & 0.071 & 0.059 & 0.071 & 229.822(0.000)\end{array}$

Notes: Panel A reports the mean, standard deviation, skewness, excess kurtosis and the BeraJarque statistic for daily log close-to-close returns for GBP/USD, CHF/USD and JPY/USD. The sample period is $01 / 01 / 87$ to $28 / 04 / 08$. Panel B reports the first six autocorrelation coefficients and the Ljung-Box Q statistic for autocorrelation up to six lags, for both returns and squared returns. P-values are reported in parentheses. 
Table 2 Root Mean Square Error

\begin{tabular}{|c|c|c|c|c|}
\hline$\tau_{2}$ & & $\mathrm{CV}$ & EGARCH (1F) & EGARCH (2F) \\
\hline \multirow[t]{3}{*}{1} & GBP & 0.00235 & 0.00264 & 0.00244 \\
\hline & $\mathrm{CHF}$ & 0.00280 & 0.00321 & 0.00333 \\
\hline & JPY & 0.00303 & 0.00336 & 0.00298 \\
\hline \multirow[t]{3}{*}{5} & GBP & 0.00133 & 0.00164 & 0.00136 \\
\hline & $\mathrm{CHF}$ & 0.00158 & 0.00177 & 0.00180 \\
\hline & JPY & 0.00190 & 0.00223 & 0.00226 \\
\hline \multirow[t]{3}{*}{20} & GBP & 0.00108 & 0.00160 & 0.00106 \\
\hline & $\mathrm{CHF}$ & 0.00119 & 0.00150 & 0.00146 \\
\hline & JPY & 0.00146 & 0.00185 & 0.00132 \\
\hline \multirow[t]{3}{*}{60} & GBP & 0.00121 & 0.00131 & 0.00129 \\
\hline & $\mathrm{CHF}$ & 0.00136 & 0.00148 & 0.00161 \\
\hline & JPY & 0.00160 & 0.00205 & 0.00174 \\
\hline \multirow[t]{3}{*}{120} & GBP & 0.00141 & 0.00172 & 0.00151 \\
\hline & $\mathrm{CHF}$ & 0.00174 & 0.00150 & 0.00145 \\
\hline & JPY & 0.00187 & 0.00181 & 0.00178 \\
\hline \multirow[t]{3}{*}{240} & GBP & 0.00170 & 0.00303 & 0.00185 \\
\hline & $\mathrm{CHF}$ & 0.00236 & 0.00242 & 0.00280 \\
\hline & JPY & 0.00243 & 0.00193 & 0.00284 \\
\hline
\end{tabular}

Notes: The table reports the Root Mean Square Error (RMSE) for the cyclical volatility model, the 1-factor range-based EGARCH model and the 2-factor range-based EGARCH model for the forecast interval $t+\tau_{1}$ to $t+\tau_{2}$, where $\tau_{1}=\max \left(1, \tau_{2}-20\right)$ for the three currencies. The evaluation sample is 06 December 1988 to 28 April 2008 (5047 observations). Each model is estimated recursively using an estimation sample of 500 observations. At each date $t$, each model is used to generate forecasts of standard deviation over the interval $t+\tau_{1}$ to $t+\tau_{2}$. These forecasts are averaged and compared with the average value of the actual standard deviation over the same interval, estimated using equation (2). 
Table 3 Mincer-Zarnowitz Regression Results $\left(\tau_{1}=1, \tau_{2}=1\right)$

\begin{tabular}{|c|c|c|c|c|c|c|c|c|c|c|c|c|}
\hline & \multicolumn{4}{|c|}{ GBP } & \multicolumn{4}{|c|}{$\mathrm{CHF}$} & \multicolumn{4}{|c|}{ JPY } \\
\hline & $\alpha$ & $\beta$ & $R^{2}$ & $F$ & $\alpha$ & $\beta$ & $R^{2}$ & $F$ & $\alpha$ & $\beta$ & $R^{2}$ & $F$ \\
\hline $\mathrm{CV}$ & $\begin{array}{c}0.092 \\
(0.013)\end{array}$ & $\begin{array}{c}0.812 \\
(0.025)\end{array}$ & 0.169 & 27.330 & $\begin{array}{c}0.146 \\
(0.019)\end{array}$ & $\begin{array}{c}0.762 \\
(0.030)\end{array}$ & 0.113 & 31.373 & $\begin{array}{c}0.099 \\
(0.015)\end{array}$ & $\begin{array}{c}0.825 \\
(0.025)\end{array}$ & 0.180 & 25.012 \\
\hline EGARCH (1F) & $\begin{array}{c}0.134 \\
(0.015)\end{array}$ & $\begin{array}{c}0.608 \\
(0.024)\end{array}$ & 0.110 & 498.473 & $\begin{array}{c}0.285 \\
(0.022)\end{array}$ & $\begin{array}{c}0.444 \\
(0.030)\end{array}$ & 0.041 & 595.976 & $\begin{array}{c}0.045 \\
(0.022)\end{array}$ & $\begin{array}{c}0.766 \\
(0.032)\end{array}$ & 0.101 & 348.220 \\
\hline EGARCH (2F) & $\begin{array}{c}0.118 \\
(0.016)\end{array}$ & $\begin{array}{c}0.749 \\
(0.030)\end{array}$ & 0.105 & 34.794 & $\begin{array}{c}0.440 \\
(0.052)\end{array}$ & $\begin{array}{c}0.379 \\
(0.080)\end{array}$ & 0.018 & 39.515 & $\begin{array}{c}0.018 \\
(0.016)\end{array}$ & $\begin{array}{c}0.998 \\
(0.028)\end{array}$ & 0.198 & 7.599 \\
\hline
\end{tabular}

\footnotetext{
Notes: The table reports the estimated intercept, slope and R-squared of the Mincer-Zarnowitz regression for the cyclical volatility model, the 1factor range-based EGARCH model and the 2-factor range-based EGARCH model for the forecast interval $t+\tau_{1}$ to $t+\tau_{2}$ for the three currencies. Standard errors for the estimated parameters are reported in parentheses. The estimated slope coefficient and standard error are multiplied by 100. The table also reports the F-statistic for the null hypothesis that the intercept is equal to zero and the slope is equal to one. The five percent critical value of the F-statistic is 2.99. The evaluation sample is 06 December 1988 to 28 April 2008 (5047 observations). Each model is estimated recursively using an estimation sample of 500 observations. At each date $t$, each model is used to generate forecasts of standard deviation over the interval $t+\tau_{1}$ to $t+\tau_{2}$. These forecasts are averaged and compared with the average value of the actual standard deviation over the same interval, estimated using equation (2).
} 
Table 4 Mincer-Zarnowitz Regression Results $\left(\tau_{1}=1, \tau_{2}=5\right)$

\begin{tabular}{|c|c|c|c|c|c|c|c|c|c|c|c|c|}
\hline & \multicolumn{4}{|c|}{ GBP } & \multicolumn{4}{|c|}{$\mathrm{CHF}$} & \multicolumn{4}{|c|}{ JPY } \\
\hline & $\alpha$ & $\beta$ & $R^{2}$ & $F$ & $\alpha$ & $\beta$ & $R^{2}$ & $F$ & $\alpha$ & $\beta$ & $R^{2}$ & $F$ \\
\hline $\mathrm{CV}$ & $\begin{array}{c}0.107 \\
(0.016)\end{array}$ & $\begin{array}{c}0.784 \\
(0.033)\end{array}$ & 0.365 & 22.002 & $\begin{array}{c}0.176 \\
(0.024)\end{array}$ & $\begin{array}{c}0.711 \\
(0.038)\end{array}$ & 0.254 & 28.193 & $\begin{array}{c}0.154 \\
(0.021)\end{array}$ & $\begin{array}{c}0.728 \\
(0.035)\end{array}$ & 0.297 & 29.678 \\
\hline EGARCH (1F) & $\begin{array}{c}0.223 \\
(0.017)\end{array}$ & $\begin{array}{c}0.624 \\
(0.038)\end{array}$ & 0.213 & 141.26 & $\begin{array}{c}0.314 \\
(0.027)\end{array}$ & $\begin{array}{c}0.504 \\
(0.046)\end{array}$ & 0.107 & 66.886 & $\begin{array}{c}0.274 \\
(0.024)\end{array}$ & $\begin{array}{c}0.584 \\
(0.047)\end{array}$ & 0.133 & 97.026 \\
\hline EGARCH (2F) & $\begin{array}{c}0.092 \\
(0.019)\end{array}$ & $\begin{array}{c}0.838 \\
(0.038)\end{array}$ & 0.327 & 15.383 & $\begin{array}{c}0.319 \\
(0.020)\end{array}$ & $\begin{array}{c}0.473 \\
(0.032)\end{array}$ & 0.175 & 131.976 & $\begin{array}{c}0.288 \\
(0.020)\end{array}$ & $\begin{array}{c}0.468 \\
(0.032)\end{array}$ & 0.180 & 148.789 \\
\hline
\end{tabular}

Notes: The table reports the estimated intercept, slope and R-squared of the Mincer-Zarnowitz regression for the cyclical volatility model, the 1factor range-based EGARCH model and the 2-factor range-based EGARCH model for the forecast interval $t+\tau_{1}$ to $t+\tau_{2}$ for the three currencies. Standard errors for the estimated parameters are reported in parentheses. The estimated slope coefficient and standard error are multiplied by 100. The table also reports the F-statistic for the null hypothesis that the intercept is equal to zero and the slope is equal to one. The five percent critical value of the F-statistic is 2.99. The evaluation sample is 06 December 1988 to 28 April 2008 (5047 observations). Each model is estimated recursively using an estimation sample of 500 observations. At each date $t$, each model is used to generate forecasts of standard deviation over the interval $t+\tau_{1}$ to $t+\tau_{2}$. These forecasts are averaged and compared with the average value of the actual standard deviation over the same interval, estimated using equation (2). 
Table 5 Mincer-Zarnowitz Regression Results $\left(\tau_{1}=1, \tau_{2}=20\right)$

\begin{tabular}{|c|c|c|c|c|c|c|c|c|c|c|c|c|}
\hline & \multicolumn{4}{|c|}{ GBP } & \multicolumn{4}{|c|}{$\mathrm{CHF}$} & \multicolumn{4}{|c|}{ JPY } \\
\hline & $\alpha$ & $\beta$ & $R^{2}$ & $F$ & $\alpha$ & $\beta$ & $R^{2}$ & $F$ & $\alpha$ & $\beta$ & $R^{2}$ & $F$ \\
\hline $\mathrm{CV}$ & $\begin{array}{c}0.147 \\
(0.026)\end{array}$ & $\begin{array}{c}0.703 \\
(0.051)\end{array}$ & 0.435 & 17.195 & $\begin{array}{c}0.230 \\
(0.034)\end{array}$ & $\begin{array}{c}0.623 \\
(0.055)\end{array}$ & 0.338 & 23.325 & $\begin{array}{c}0.202 \\
(0.031)\end{array}$ & $\begin{array}{c}0.641 \\
(0.052)\end{array}$ & 0.375 & 23.489 \\
\hline EGARCH (1F) & $\begin{array}{c}0.274 \\
(0.025)\end{array}$ & $\begin{array}{c}0.550 \\
(0.061)\end{array}$ & 0.243 & 116.972 & $\begin{array}{c}0.393 \\
(0.040)\end{array}$ & $\begin{array}{c}0.351 \\
(0.064)\end{array}$ & 0.107 & 51.523 & $\begin{array}{c}0.317 \\
(0.031)\end{array}$ & $\begin{array}{c}0.504 \\
(0.060)\end{array}$ & 0.218 & 66.265 \\
\hline EGARCH (2F) & $\begin{array}{c}0.115 \\
(0.030)\end{array}$ & $\begin{array}{c}0.784 \\
(0.061)\end{array}$ & 0.398 & 8.063 & $\begin{array}{c}0.371 \\
(0.037)\end{array}$ & $\begin{array}{c}0.406 \\
(0.062)\end{array}$ & 0.147 & 50.588 & $\begin{array}{c}0.090 \\
(0.037)\end{array}$ & $\begin{array}{c}0.864 \\
(0.066)\end{array}$ & 0.408 & 3.937 \\
\hline
\end{tabular}

Notes: The table reports the estimated intercept, slope and R-squared of the Mincer-Zarnowitz regression for the cyclical volatility model, the 1factor range-based EGARCH model and the 2-factor range-based EGARCH model for the forecast interval $t+\tau_{1}$ to $t+\tau_{2}$ for the three currencies. Standard errors for the estimated parameters are reported in parentheses. The estimated slope coefficient and standard error are multiplied by 100. The table also reports the F-statistic for the null hypothesis that the intercept is equal to zero and the slope is equal to one. The five percent critical value of the F-statistic is 2.99. The evaluation sample is 06 December 1988 to 28 April 2008 (5047 observations). Each model is estimated recursively using an estimation sample of 500 observations. At each date $t$, each model is used to generate forecasts of standard deviation over the interval $t+\tau_{1}$ to $t+\tau_{2}$. These forecasts are averaged and compared with the average value of the actual standard deviation over the same interval, estimated using equation (2). 
Table 6 Mincer-Zarnowitz Regression Results $\left(\tau_{1}=41, \tau_{2}=60\right)$

\begin{tabular}{|c|c|c|c|c|c|c|c|c|c|c|c|c|}
\hline & \multicolumn{4}{|c|}{ GBP } & \multicolumn{4}{|c|}{$\mathrm{CHF}$} & \multicolumn{4}{|c|}{ JPY } \\
\hline & $\alpha$ & $\beta$ & $R^{2}$ & $F$ & $\alpha$ & $\beta$ & $R^{2}$ & $F$ & $\alpha$ & $\beta$ & $R^{2}$ & $F$ \\
\hline $\mathrm{CV}$ & $\begin{array}{c}0.231 \\
(0.045)\end{array}$ & $\begin{array}{c}0.519 \\
(0.090)\end{array}$ & 0.290 & 14.434 & $\begin{array}{c}0.339 \\
(0.064)\end{array}$ & $\begin{array}{c}0.442 \\
(0.103)\end{array}$ & 0.183 & 14.630 & $\begin{array}{c}0.332 \\
(0.049)\end{array}$ & $\begin{array}{c}0.378 \\
(0.085)\end{array}$ & 0.193 & 27.050 \\
\hline EGARCH (1F) & $\begin{array}{c}0.240 \\
(0.028)\end{array}$ & $\begin{array}{c}0.514 \\
(0.055)\end{array}$ & 0.261 & 39.412 & $\begin{array}{c}0.405 \\
(0.046)\end{array}$ & $\begin{array}{c}0.336 \\
(0.074)\end{array}$ & 0.076 & 39.997 & $\begin{array}{c}0.420 \\
(0.039)\end{array}$ & $\begin{array}{c}0.249 \\
(0.064)\end{array}$ & 0.057 & 68.766 \\
\hline EGARCH $(2 F)$ & $\begin{array}{c}0.217 \\
(0.030)\end{array}$ & $\begin{array}{c}0.539 \\
(0.058)\end{array}$ & 0.257 & 34.069 & $\begin{array}{c}0.427 \\
(0.037)\end{array}$ & $\begin{array}{c}0.292 \\
(0.058)\end{array}$ & 0.091 & 74.120 & $\begin{array}{c}0.298 \\
(0.039)\end{array}$ & $\begin{array}{c}0.467 \\
(0.066)\end{array}$ & 0.170 & 33.355 \\
\hline
\end{tabular}

Notes: The table reports the estimated intercept, slope and R-squared of the Mincer-Zarnowitz regression for the cyclical volatility model, the 1factor range-based EGARCH model and the 2-factor range-based EGARCH model for the forecast interval $t+\tau_{1}$ to $t+\tau_{2}$ for the three currencies. Standard errors for the estimated parameters are reported in parentheses. The estimated slope coefficient and standard error are multiplied by 100. The table also reports the F-statistic for the null hypothesis that the intercept is equal to zero and the slope is equal to one. The five percent critical value of the F-statistic is 2.99. The evaluation sample is 06 December 1988 to 28 April 2008 (5047 observations). Each model is estimated recursively using an estimation sample of 500 observations. At each date $t$, each model is used to generate forecasts of standard deviation over the interval $t+\tau_{1}$ to $t+\tau_{2}$. These forecasts are averaged and compared with the average value of the actual standard deviation over the same interval, estimated using equation (2). 
Table 7 Mincer-Zarnowitz Regression Results $\left(\tau_{1}=101, \tau_{2}=120\right)$

\begin{tabular}{|c|c|c|c|c|c|c|c|c|c|c|c|c|}
\hline & \multicolumn{4}{|c|}{ GBP } & \multicolumn{4}{|c|}{$\mathrm{CHF}$} & \multicolumn{4}{|c|}{ JPY } \\
\hline & $a$ & $b$ & $R^{2}$ & $F$ & $a$ & $b$ & $R^{2}$ & $F$ & $a$ & $b$ & $R^{2}$ & $F$ \\
\hline $\mathrm{CV}$ & $\begin{array}{c}0.257 \\
(0.076)\end{array}$ & $\begin{array}{c}0.483 \\
(0.149)\end{array}$ & 0.208 & 6.000 & $\begin{array}{c}0.458 \\
(0.101)\end{array}$ & $\begin{array}{c}0.241 \\
(0.162)\end{array}$ & 0.052 & 10.949 & $\begin{array}{c}0.428 \\
(0.078)\end{array}$ & $\begin{array}{c}0.182 \\
(0.138)\end{array}$ & 0.042 & 17.976 \\
\hline EGARCH (1F) & $\begin{array}{c}0.346 \\
(0.022)\end{array}$ & $\begin{array}{c}0.317 \\
(0.046)\end{array}$ & 0.159 & 119.087 & $\begin{array}{c}0.336 \\
(0.088)\end{array}$ & $\begin{array}{c}0.407 \\
(0.131)\end{array}$ & 0.038 & 35.985 & $\begin{array}{c}0.390 \\
(0.064)\end{array}$ & $\begin{array}{c}0.302 \\
(0.109)\end{array}$ & 0.030 & 21.259 \\
\hline EGARCH (2F) & $\begin{array}{c}0.307 \\
(0.027)\end{array}$ & $\begin{array}{c}0.386 \\
(0.055)\end{array}$ & 0.169 & 66.070 & $\begin{array}{c}0.347 \\
(0.063)\end{array}$ & $\begin{array}{c}0.405 \\
(0.096)\end{array}$ & 0.068 & 29.827 & $\begin{array}{c}0.353 \\
(0.062)\end{array}$ & $\begin{array}{c}0.365 \\
(0.105)\end{array}$ & 0.047 & 19.499 \\
\hline
\end{tabular}

Notes: The table reports the estimated intercept, slope and R-squared of the Mincer-Zarnowitz regression for the cyclical volatility model, the 1factor range-based EGARCH model and the 2-factor range-based EGARCH model for the forecast interval $t+\tau_{1}$ to $t+\tau_{2}$ for the three currencies. Standard errors for the estimated parameters are reported in parentheses. The estimated slope coefficient and standard error are multiplied by 100. The table also reports the F-statistic for the null hypothesis that the intercept is equal to zero and the slope is equal to one. The five percent critical value of the F-statistic is 2.99. The evaluation sample is 06 December 1988 to 28 April 2008 (5047 observations). Each model is estimated recursively using an estimation sample of 500 observations. At each date $t$, each model is used to generate forecasts of standard deviation over the interval $t+\tau_{1}$ to $t+\tau_{2}$. These forecasts are averaged and compared with the average value of the actual standard deviation over the same interval, estimated using equation (2). 
Table 8 Mincer-Zarnowitz Regression Results $\left(\tau_{1}=221, \tau_{2}=240\right)$

\begin{tabular}{|c|c|c|c|c|c|c|c|c|c|c|c|c|}
\hline & $\alpha$ & $\beta$ & $R^{2}$ & $F$ & $\alpha$ & $\beta$ & $R^{2}$ & $F$ & $\alpha$ & $\beta$ & $R^{2}$ & $F$ \\
\hline $\mathrm{CV}$ & $\begin{array}{c}0.424 \\
(0.127)\end{array}$ & $\begin{array}{c}0.169 \\
(0.241)\end{array}$ & 0.025 & 5.968 & $\begin{array}{c}0.818 \\
(0.135)\end{array}$ & $\begin{array}{c}-0.329 \\
(0.209)\end{array}$ & 0.115 & 20.288 & $\begin{array}{c}0.509 \\
(0.129)\end{array}$ & $\begin{array}{c}0.052 \\
(0.218)\end{array}$ & 0.003 & 9.692 \\
\hline $\mathrm{RCH}(2 \mathrm{~F})$ & $\begin{array}{c}0.484 \\
(0.008)\end{array}$ & $\begin{array}{l}-0.000 \\
(0.000)\end{array}$ & 0.001 & 538.031 & $\begin{array}{c}0.604 \\
(0.009)\end{array}$ & $\begin{array}{c}0.003 \\
(0.003)\end{array}$ & 0.003 & 63012.596 & $\begin{array}{c}0.531 \\
(0.030)\end{array}$ & $\begin{array}{c}0.054 \\
(0.046)\end{array}$ & 0.006 & 215.064 \\
\hline
\end{tabular}

Notes: The table reports the estimated intercept, slope and R-squared of the Mincer-Zarnowitz regression for the cyclical volatility model, the 1factor range-based EGARCH model and the 2-factor range-based EGARCH model for the forecast interval $t+\tau_{1}$ to $t+\tau_{2}$ for the three currencies. Standard errors for the estimated parameters are reported in parentheses. The estimated slope coefficient and standard error are multiplied by 100 . The table also reports the F-statistic for the null hypothesis that the intercept is equal to zero and the slope is equal to one. The five percent critical value of the F-statistic is 2.99. The evaluation sample is 06 December 1988 to 28 April 2008 (5047 observations). Each model is estimated recursively using an estimation sample of 500 observations. At each date $t$, each model is used to generate forecasts of standard deviation over the interval $t+\tau_{1}$ to $t+\tau_{2}$. These forecasts are averaged and compared with the average value of the actual standard deviation over the same interval, estimated using equation (2). 